Instructions for authors, subscriptions and further details:

http://brac.hipatiapress.com

\title{
Reflexiones acerca del Mail Art Latinoamericano
}

Fabiane Pianowski ${ }^{1}$

1) Universidade Federal do Vale do São Francisco. Brasil

Date of publication: October $3^{\text {rd }}, 2014$

Edition period: October 2014-February 2015

To cite this article: Pianowski, F. (2014). Reflexiones acerca del Mail Art Latinoamericano. Barcelona, Research, Art, Creation, 2(3), 327-348. doi: 10.4471/brac.2014.16

To link this article: http://dx.doi.org/10.4471/brac.2014.16

\section{PLEASE SCROLL DOWN FOR ARTICLE}

The terms and conditions of use, except where otherwise noted, are related to the Open Journal System and to Creative Commons Attribution License (CCBY). The indication must be expressly stated when necessary. 
BRAC - Barcelona Research Art Creation. Vol. 2 No. 3, October 2014, pp. 327-348

\title{
Reflections on Latin American Mail Art
}

Fabiane Pianowski

Universidade Federal do Vale do São Francisco

(Received: 28 April 2014; Accepted: 10 August 2014; Published: 3 October 2014)

\begin{abstract}
Breaking away from the official circuits of art galleries and museums, mail art heralds a new era for the circulation of artistic work, which focuses primarily on the collective. This alternative means of circulation for artistic proposals and ideas brings forward the concept of network that would later, with the birth of the Internet, become a highly significant issue for contemporaneity. The use of mail in the 1960s and 1970s as a tactical instrument in the field of art relates to the appropriation of the means of communication by the period's artistic manifestations - a period in which establishing networks and communicating were crucial cultural elements. In so doing, mail art democratizes art. Unfortunately, there are few academic studies about mail art, probably because that field of study is obdurately complex, the information is difficult to obtain. It is difficult to accurate facts and datas. The documents and works were frequently intend as ephemera. In spite of that, in this doctoral thesis we analyse in depth mail artists' publications and interviews to understand their communicational connections and strategies, particularly in the field of Latin America.
\end{abstract}

Keywords: mail art, networks, communication, history, Latin America 
BRAC - Barcelona Research Art Creation. Vol. 2 No. 3, October 2014, pp. 327-348

\section{Reflexiones acerca del Mail Art Latinoamericano}

Fabiane Pianowski

Universidade Federal do Vale do São Francisco

(Recibido: 28 Abril 2014; Aceptado: 10 Agosto 2014; Publicado: 3 Octubre 2014)

\section{Resumen}

Rompiendo con los circuitos oficiales de las galerías y museos, el mail art enuncia una nueva forma de circulación del trabajo artístico, que enfatiza sobre todo lo colectivo. Este modo alternativo de circulación de las proposiciones/ideas artísticas enunciaba la idea de red que, posteriormente, con el adviento de Internet, se haría una cuestión altamente relevante para la contemporaneidad. En los años 1960 y 1970, el uso de los Correos como un medio táctico en el ámbito del arte está relacionado con la apropiación de los medios de comunicación por parte de las manifestaciones artísticas del periodo - un periodo en que la creación de redes y la comunicación eran fundamentales. El objetivo del mail art es romper con el flujo unidireccional emisor-receptor de los medios de comunicación de masa, a través de la participación activa del espectador en la obra, socializando la autoría y diluyendo las fronteras que separan artista y público. Es difícil precisar hechos y fechas. Los documentos y producciones son efímeros. A pesar de esto, en esta tesis doctoral se han analizado en profundidad las publicaciones en mail art y las declaraciones de los artistas para entender sus conexiones y estrategias de comunicación, especialmente en el ámbito latinoamericano.

Palabras clave: mail art, redes, comunicación, historia, Latinoamérica 


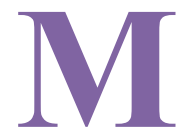

ail art es la puesta en circulación, a través del sistema postal, de las más diferentes propuestas estéticas. Funciona a través de una red de artistas en la cual el principal objetivo no es tanto la exhibición de la producción artística sino la comunicación y el intercambio de ideas. De manera que el enfoque del mail art no está centrado en el objeto artístico sino en el proceso, es decir, en las relaciones que se establecen en esta red.

El mail art se conecta con diferentes manifestaciones artísticas de la historia del arte, tanto por el uso del correo como por la práctica colectiva: las primeras vanguardias del siglo XX (figura 1), los nuevos realistas, los artistas Fluxus y el arte conceptual, por citar las más sobresalientes. Sin embargo, los expertos - que apenas se preocupan con el tema, probablemente por tratarse de un tema marginal al canon - suelen considerar la práctica del mail art como una de las innumerables propuestas del fenómeno artístico denominado conceptualismo, cuyo énfasis se encuentra en la idea, en el proceso, en la desmaterialización y en lo efímero del arte.

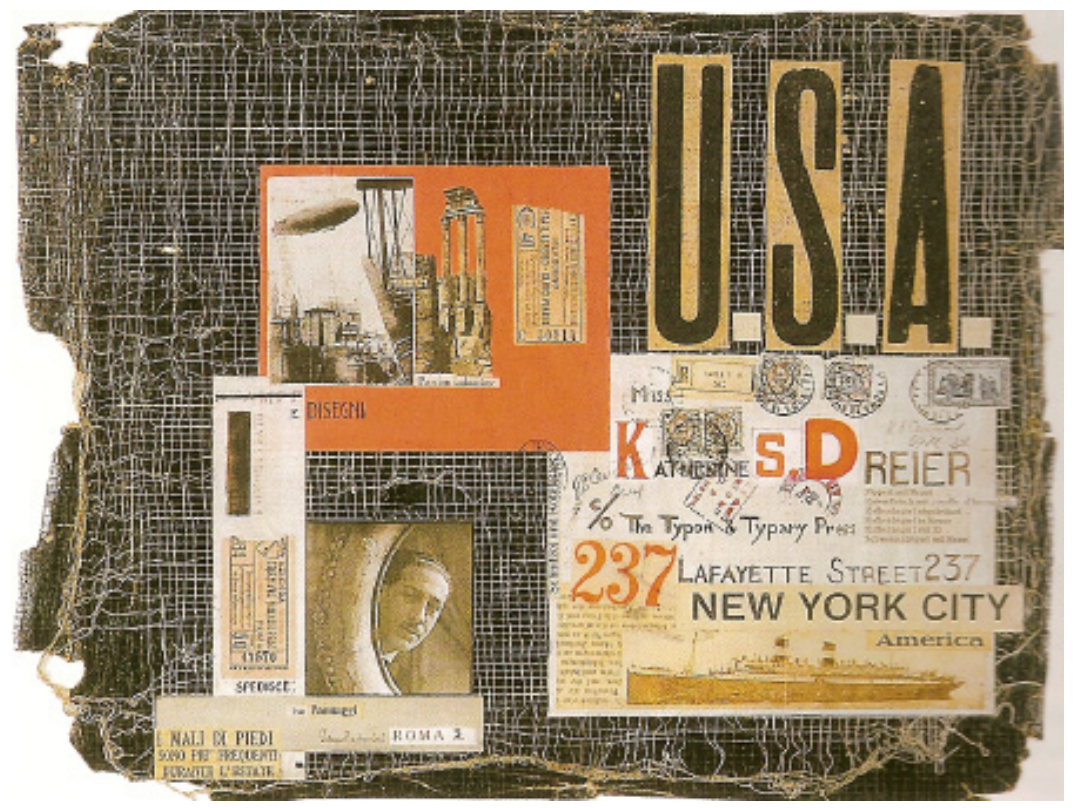

Figura 1. Ivo Pannaggi, Collage postal, 1926 - remitida a Katherine Dreier el 16/10/1926. Fuente: Fuente: (Bernard, 2005). 
En gran parte de la bibliografía que trata de la historia del mail art a partir de un enfoque internacional se indica que el mail art latinoamericano tiene un carácter particular en relación a los demás por presentarse como una práctica artística políticamente comprometida. En cierta medida este enfoque corrobora la teoría del conceptualismo ideológico de Marchán Fiz (1972). Bajo esta perspectiva, a través del estudio de las motivaciones de los artistas correo se ha pretendido averiguar si la repercusión del sistema político dictatorial ha influido tanto en el arte y la cultura hasta el punto de que se pueda considerar que el mail art latinoamericano se ha distinguido del resto del mundo. En este sentido, la decisión ha sido dar prioridad al artista-autor de mail art, a fin de determinar cuál es la figura del artista correo y por qué motivos participa en la red.

Cabe llamar la atención a la terminología empleada en los estudios del mail art, puesto que a pesar de mail art ser la grafía más común, el término también puede aparecer escrito todo junto "mailart" o con guión "mail-art". Guy Bleus (1984), que suele utilizar Mail-Art en mayúsculas y con guión, apunta varios sinónimos para el término: post art, postal art, art-mail, correspondence art, destacando también los usos regionales como arte postale (Italia), post-kunst (Alemania y Países Bajos), sztuka poczty (Polonia), art postale (Francia), y arte correo o arte postal (España, América del Sur y México). Mientras tanto, en Brasil el término más utilizado es arte postal, pero algunos artistas, por otro lado, prefieren el término arte por correspondência.

\section{Cuestionando los Estereotipos}

En la mayoría de los textos revisados los autores diferencian el conceptualismo latinoamericano de los sesenta y setenta por su carácter político-ideológico, que es vinculando directamente a su contexto político (Camnitzer, 1997, 2009; Freire, 1999, 2006; Marchán Fiz, 1994; Osborne, 2006 y Wood, 2002). Esta categorización conlleva a una visión nacionalista del conceptualismo — distinta de la visión más internacionalista planteada por Lippard (2004) y Marzona (2005) — en la que la etiqueta "ideológica" o "política" acaba por asociarse estrictamente a determinados contextos.

Llamando la atención sobre los riesgos de reafirmar los estereotipos por el uso de la etiqueta "conceptualismo ideológico", Zanna Gilbert (2009) defiende que los aspectos político-ideológicos del conceptualismo, al ser restringido hasta finales de los setenta a Latinoamérica, pueden caer en una lectura 
limitada y con prejuicios de esa producción artística. Esa categorización, para la investigadora, puede establecer una visión de Latinoamérica como "melancólica, violenta e inestable", es decir un perfecto "otro" en oposición a la "democrática y estable" Norteamérica y Europa, reafirmando estereotipos. Al mismo tiempo, Gilbert señala como un problema del uso de la etiqueta "conceptualismo ideológico" el riesgo de restringir el contenido ideológico a una iconografía directa, en la que se sobrestima el contenido en detrimento de la forma, anulando la posible ambigüedad entre forma e idea de muchas producciones, cayendo en simplificaciones de lectura.

Al relacionar las perspectivas teóricas acerca del arte conceptual y del conceptualismo latinoamericano no sólo es posible verificar la tendencia general a nacionalizar y definir como político-ideológicas estas manifestaciones artísticas, sino que también demuestra como los planteamientos de Global Conceptualism fueron a la vez esclarecedores y sintetizadores, sin caer en la estereotipación de las etiquetas deterministas y generalizantes.

En lo que se refiere al mail art, este tuvo un papel extremadamente relevante en el contexto de los estados totalitarios, una vez que la emisión y la recepción de mensajes artísticos dejan de estar vinculados a los espacios privilegiados de las instituciones oficiales - como galerías y museos - pasando a ocupar artísticamente los intersticios de la trama social a través de la utilización de los servicios de correos, de espacios alternativos y del ambiente doméstico y privado. La actuación en redes de intercambio alternativas confiere a las operaciones del mail art un estatus de colectividad, que funcionaban en aquel momento subversivamente como una guerrilla subterránea y rizomática de ideas y conceptos ético-estéticos. La red postal se convertía entonces en un lugar de asociaciones temporales donde el arte y la política se encontraban (figura 2). Pero, ¿es posible afirmar que el mail art latinoamericano tiene un acento político-ideológico marcado que lo diferencia de los demás sin caer en una estereotipación? Y más, ¿es posible escribir una historia descentralizada del mail art en que se borre la dicotomía centro-periferia? 


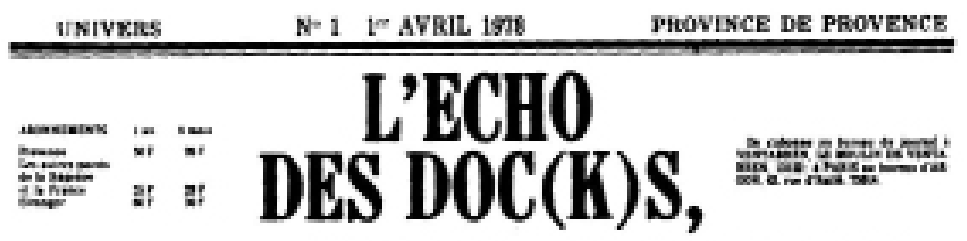

JOURNAI. D DANNONCES, POETIQUES, AETISTIQUES FT LTTKRAIRES jeraksane queleuefoia
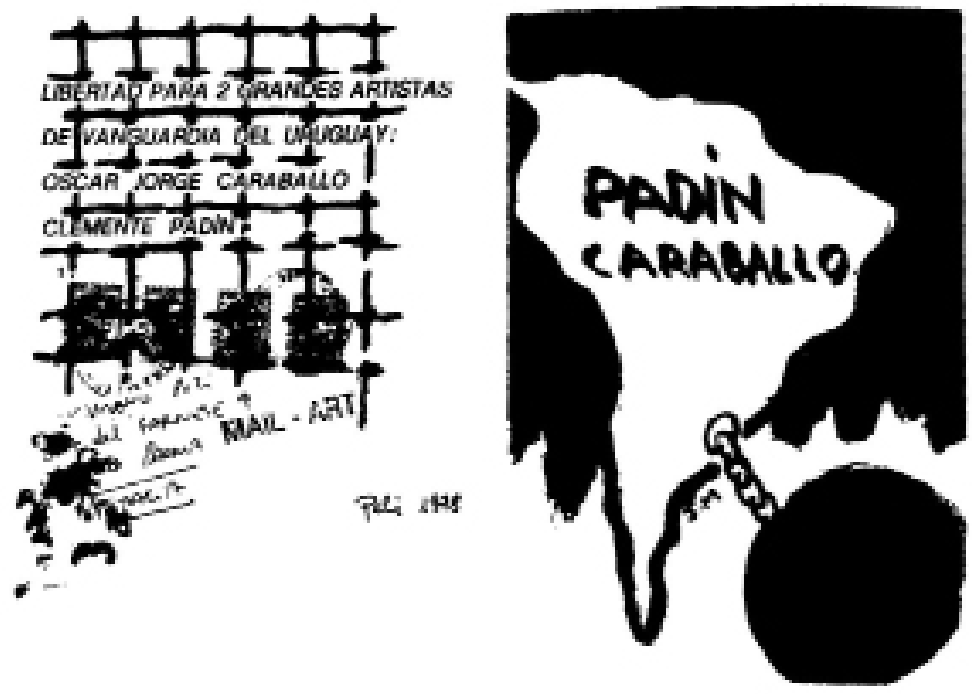

JONIER MARIN

Figura 2. Julien Blaine, revista L'Echo de Doc(k)s, n.1, dos trabajos publicados acerca del aprisionamiento de Clemente Padín y Jorge Caraballo. Izquierda: Romano Peli, sin título, Itália, 1978. Derecha: Jonier Marin, Padín/Caraballo, Colombia, 1978. Fuente: (Crane \& Stofflet, 1984).

Analizar la historia del mail art latinoamericano, bajo una perspectiva descentralizada que vaya de lo local hacía lo global y viceversa, destacando sus particularidades y enmarcando sus conexiones con el movimiento internacional del mail art ha sido el principal desafío planteado por la investigación doctoral en Historia del Arte desarrollada en la Universidad de Barcelona, en que parte de los resultados se presentan en este artículo. 


\section{Conceptuando la Red de Mail Art}

Según Osborne (2006), la utilización de diferentes medios de distribución de las proposiciones artísticas - como el fax, teléfono, correspondencia electrónica, vídeo, audio, correos etc. - estaba relacionado con la necesidad del arte conceptual de requerir la participación del público, con el fin de desafiar la percepción contemplativa de la obra y al mismo tiempo romper con las categorías convencionales del objeto de arte que derivaban en relaciones mercantiles. Rompiendo con los circuitos oficiales de las galerías y museos, el mail art enuncia una nueva forma de circulación del trabajo artístico, que enfatiza sobre todo lo colectivo (figura 3).

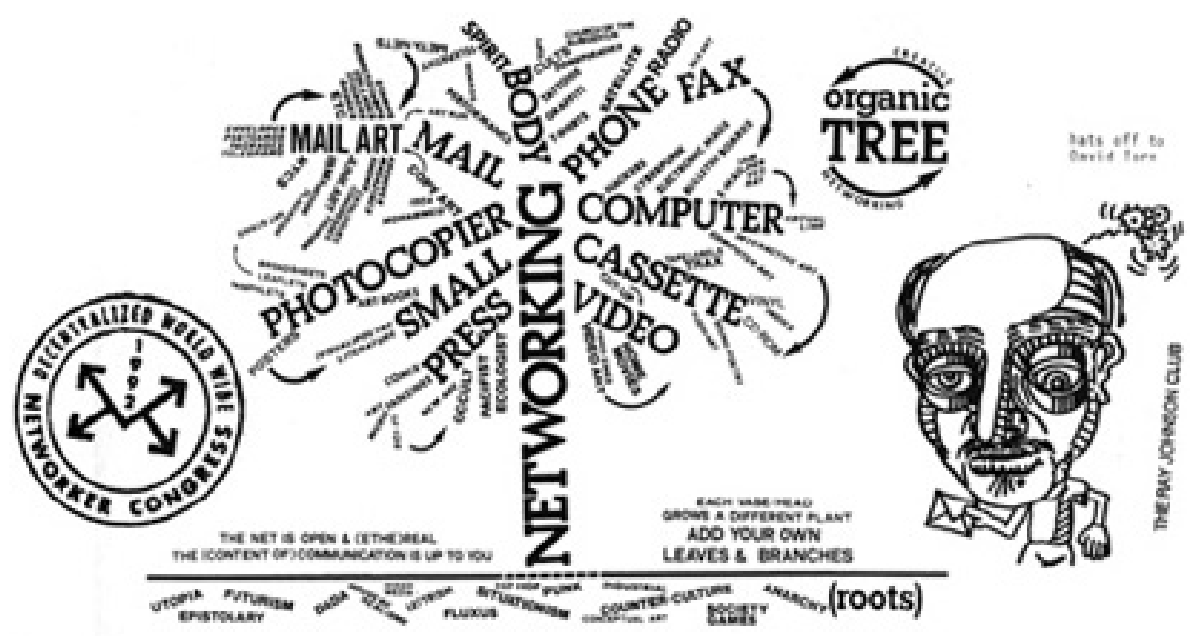

Figura 3. Julien Vittore Baroni, Networking tree, 1982, Ilustración para Arte Postale!, n.63. Fuente: (Baroni, 1995).

La experimentación y la explotación de nuevos medios, técnicas y circuitos de exhibición fueron fundamentales para el desarrollo del arte conceptual $y$, en especial, del mail art. Como ejemplo de esta relación existe no sólo el propio correo, con su amplia accesibilidad y amplitud, sino también el uso de tecnologías recientes en aquel momento como la fotocopia que, por ejemplo, posibilitaba la reproducción en grandes cantidades de modo rápido y relativamente barato de las propuestas artísticas que posteriormente circularían en la red. 
A principios de los noventa la tecnología digital empieza a utilizarse efectivamente en el ámbito artístico, floreciendo en la red de mail art conjeturas acerca de las perspectivas del uso del fax, del ordenador y sobre todo de Internet. La aparición de los nuevos medios ha generado innumerables expectativas, casi siempre positivas y entusiastas, ya que eran pocos los que tenían una visión más escéptica o conservadora acerca del futuro de la red y su relación con ellos.

En la red de mail art cualquiera puede, con la mayor libertad, entrar o salir en cualquier momento, siendo este flujo continuo su movimiento vital. No hay un líder o una publicación central. Las listas de direcciones de los participantes son la alimentación de la red y actúan en su expansión, pues a través de ellas se amplían las posibilidades de contacto entre individuos que tienen los mismos intereses y no se conocen. La red no está formada por un único circuito y sí por innumerables circuitos que se entrecruzan y se relacionan de manera nojerárquica. Bajo esta perspectiva, la teoría del rizoma de Deleuze \& Guattari (1997) se ajusta a la interpretación de la red de mail art, de modo que facilita a el entendimiento de su funcionamiento y a la comprensión de la filosofía que comparten los artistas y que sostiene su dinámica, una vez que permite que la red de mail art sea entendida como un sistema dinámico, múltiple y no-jerárquico, aspectos que igualmente son destacados por los estudios de los medios relativos al concepto de red.

Aparte del concepto de rizoma también es interesante pensar en la red de mail art bajo la perspectiva del estudio de lo medios a fin de profundizar la comprensión de su estructura y funcionamiento. En este sentido, el artículo intitulado "Network" de Alexander Galloway (2010) es bastante significativo porque hace una revisión histórica acerca del tema de las redes.

El autor destaca que la constitución de redes siempre ha existido, no siendo algo endémico a este siglo o al siglo pasado. Para el autor es la tendencia a asociar red y tecnología que nos lleva a considerar ese tema como algo reciente y, en cierto sentido, innovador. Sin embargo, lo que sí es interesante y novedoso es el entendimiento del funcionamiento de las redes a través del uso de los nuevos medios. Para Galloway, las redes son sistemas de interconectividad, entendidas como algo más que la simple agregación de las partes, puesto que deben estar en constante relación. Por lo tanto, el punto importante que se ha de considerar en el estudio de las redes es el entendimiento de como los medios pueden afectar la interconectividad.

En el mail art, la interconectividad ocurre a través del sistema postal que tiene en el tiempo de la incertidumbre y en el tiempo de la espera sus 
particularidades y ambigüedades. Esos tiempos, distintos y simultáneos, afectan al "feedback", es decir, la realimentación y autoreflexión de la propia red en sentido pluridireccional.

El feedback es el elemento responsable de la dinámica y la vitalidad de una red, y en el caso particular del mail art este aspecto está relacionado directamente con la intensidad de conexión, es decir, con la participación de cada artista en la red (cantidad de envíos, proyectos, exhibiciones, publicaciones etc.) y por lo tanto es sinónimo tanto de éxito como de calidad. Por lo tanto, es la intensidad de determinada presencia en la red lo que acaba estableciendo su reconocimiento.

Galloway presenta tres diferentes tipologías de redes: a) centralizada, b) descentralizada y c) distribuida (Baran apud Galloway, 2010, p. 288-290) que son útiles para entender la estructura de la red de mail art.

En el primer tipo, la red centralizada o estrella, existe un nudo central conectado a innumerables nudos periféricos. Esta tipología puede aplicarse a la primera fase del mail art, en la que la red estaba centralizada en la figura de Ray Johnson. En la red de Johnson, es decir, en su performance postal, todavía no había una preocupación con el feedback, de manera que gran parte de sus conexiones eran intencional y marcadamente unidireccionales, en las cuales el artista aparentemente no esperaba ningún tipo de retorno. A excepción de sus juegos de "adiciona y retorna" o "adiciona y repasa" en los cuales provocaba la respuesta. De esta manera, Johnson orquestaba sus envíos, manteniendo su red bajo control. Bajo esta perspectiva, la actuación postal de Johnson es más una performance particular del artista que hace uso del sistema postal que una actividad estrictamente relacionada a la red de mail art.

Como afirma Ina Blom, "Ray Johnson's art was not in a simple and direct way a model for what was later going to be known as mail art. In fact, in a certain sense his work was not an art of the postal system at all" (2007, p. 6). Pese a esta consideración, la ambigüedad de la performance postal de Johnson entre simultáneamente invitar y vetar la participación, es sin duda una referencia fundamental para el entendimiento del mail art.

El segundo tipo, conocido como red descentralizada en la cual se combinan innumerables subredes centralizadas, es el modelo que la historia del arte que prioriza la producción individual y está ideológicamente atada a los intereses económicos utiliza para entender los movimientos colectivos como el mail art. En esta tipología, no hay uno, sino múltiples centros, que para dicha historia corresponderían a los artistas "reconocibles" o "reconocidos", es decir, aquellos que de alguna manera pueden ser o son institucionalizados y, 
por lo tanto, cotizados en el mercado de arte.

Pese a esa tipología, en términos pragmáticos, ser útil a la comprensión de la estructura de la red, por destacar los centros y facilitar la historización de los hechos, ella ideológicamente está reafirmando las jerarquías que el mail art condena porque enmarca distinciones entre centro y periferia, artista reconocido y no-reconocido etc. Por lo tanto, aplicar este modelo de red a propuestas de colectivismo - como es el caso del mail art- es mantener el concepto de aura, cuyo centro es el artista, considerado bueno o importante, y la periferia el desconocido, el malo y desechable.

La tipología más adecuada para el entendimiento de la red de mail art es, por lo tanto, la llamada red distribuida; una tipología que genera nuevas y robustas estructuras de organización. Esta tipología se establece en concordancia con el concepto de rizoma, es decir, se distribuye de manera horizontal, múltiple y sin jerarquías. En esta red todos los nudos están interconectados y no pasan por ninguna especie de núcleo, de modo que desaparece la diferencia entre centro y periferia y con esto también se borran las posibilidades de control sobre lo que circula. Las rupturas o ausencias temporales de algunos nudos no generan desconexión entre los demás.

Con el fin de profundizar en la comprensión de la estructura y facilitar la historización de la red de mail art es necesario añadir algunas particularidades que son útiles para su comprensión. En este sentido, se puede pensar la red de mail art como una red de tipología distribuida que tiene dos tipos de nodos: fuertes y débiles. Los nudos fuertes son los artistas correo que tuvieron o tienen un intensa actividad en la red y los nudos frágiles son los artistas correo ocasionales. Esta categorización no tiene ninguna relación con calidad o importancia, solamente está vinculada a la intensidad de la conexión, es decir, lo que determina si un nudo es fuerte o débil es la capacidad de feedback de cada artista y eso puede ser cuantificado: número de producciones, publicaciones, proyectos etc.

Esos nudos pueden generar a la vez dos niveles de conexión, robusta y frágil. La intensidad de conexión puede ser particularmente útil en el análisis de la red de mail art, porque es necesario pensar esa red como una red de redes, por lo tanto a través de esa distinción es posible aislar esas subredes, que en términos concretos se materializan en los archivos particulares de cada artista. 


\section{Metodología}

La historia así como las colecciones seleccionan arbitrariamente tanto lo que debe estar presente como lo que debe ser excluido u olvidado. Esta selección - dictada por diversos factores como el mercado, la ideología, el momento político, el ambiente cultural, la moda etc.,- tiene consecuencias negativas para las proposiciones conceptuales, especialmente para aquellas consideradas periféricas o marginales como es el caso del mail art, puesto que dificulta que el proceso de escritura de una historia del arte sea realmente abarcadora y efectiva. Se suma a esta dificultad la comprensión del "arte" como algo más que un mero objeto, una vez que estos artistas operan con proyectos, documentos, acciones, performances, circuitos, archivos, redes etc., lo que muchas veces rompe con la lógica tradicionalmente asumida de obra de arte, de modo que la única evidencia que queda de lo efímero para la memoria/ historia (cuando queda) es el registro escrito o foto/ videográfico. Freire (2005) llama la atención sobre esa frecuente ambigüedad y ausencia de diferencias entre documento y obra, en la cual existe cierta intención de permanencia de algo que definitivamente se escapa. Ese arte "presente-ausente" en vez de enfocar la materialidad sensible del objeto de arte, enfatiza los modos de funcionamiento de sus proposiciones, las concepciones/percepciones del artista y el contexto socio-histórico en que estaba insertada, elementos que se hacen fundamentales para su comprensión. En el arte conceptual, el carácter "artístico" es ante todo el proceso y el análisis de la naturaleza misma de la información (Freire, 1999).

Bajo esa perspectiva, el análisis de la materialidad sensible de la obra como exclusivo parámetro de estudio queda obsoleto, haciéndose necesaria la creación de otros parámetros para el acompañamiento histórico-crítico de la producción artística realizada a partir de la instauración del arte conceptual. Puesto que el arte conceptual altera radicalmente la definición de artista, de los modos de producción, recepción y circulación del arte, agotando la crítica formalista y planteando una revisión de la narrativa dominante de la historia del arte y de sus prácticas institucionales (Freire, 2006).

Las propuestas artísticas que surgen bajo el conceptualismo instauran un nuevo paradigma artístico y requieren un estudio que, sobrepasando el análisis del objeto artístico de forma aislada, reconsidere el papel del artista, del público y de las instituciones (figura 4). Un estudio que reconstituya la intricada red simbólica que envuelve las efímeras proposiciones conceptuales. Esta red comprende el contexto políticocultural y social, el repertorio 
individual del artista, así como las condiciones de su exhibición. De este modo, el contexto para la creación artística debe ser pensado sobre una base tanto artística, incluyendo conceptos, ideas, valores y representaciones que se extiende más allá de los límites de la percepción visual, como sociológica, en que el significado de la obra es entendido a partir de un determinado sistema de valores y representaciones del cual participa (Freire, 1999).

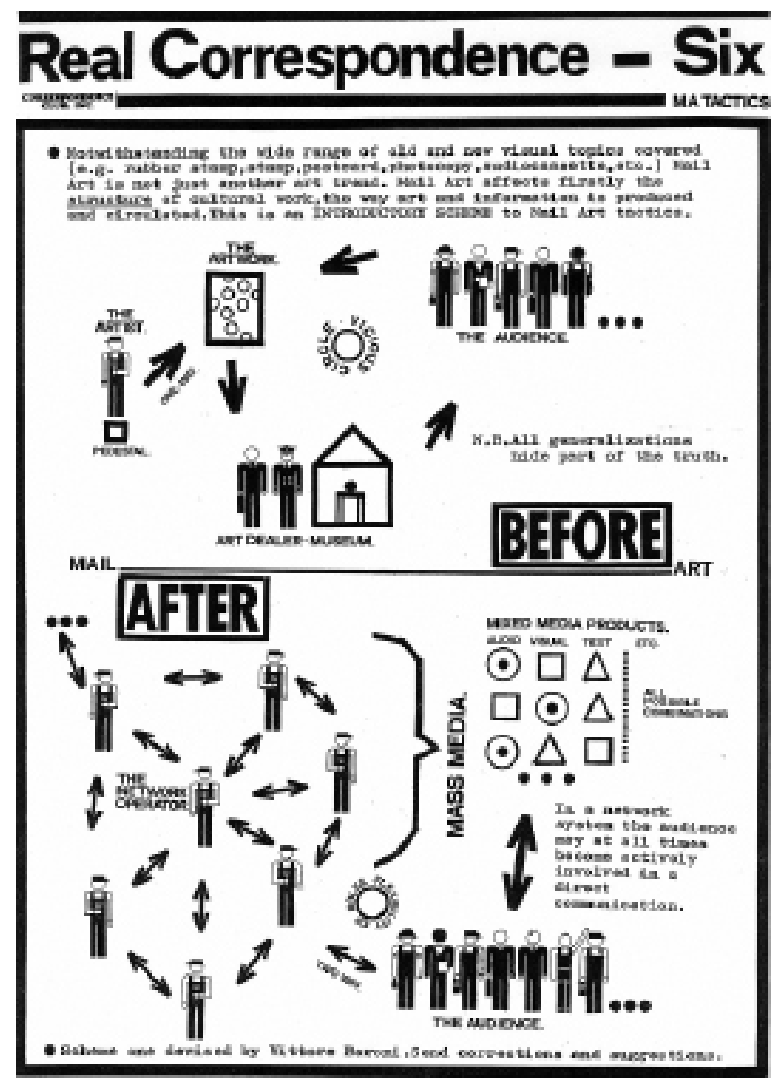

Figura 4. Vittore Baroni, esquema de la diferencia entre el mundo del arte y la red de mail art, 1981. Fuente: (Baroni, 1997).

Los asertos de la historiadora y crítica de arte Cristina Freire plantean la necesidad del uso de una metodología de investigación en arte que articule, de manera eficaz, al artista y sus poéticas con el sistema de valores y de 
representación en que estaban incluidos y en que están siendo estudiados. Cabe destacar el carácter interdisciplinario de esta metodología, que rompe con las fronteras de las disciplinas aisladas y articula los diferentes conocimientos provenientes de áreas como historia, antropología, sociología, psicoanálisis, filosofía etc. Está en la interdisciplinariedad el punto clave del conceptualismo, puesto que mismo en sus apariciones más "convencionales" se presenta abierto a disciplinas tan variadas como la lingüística, la teoría de sistemas, la filosofía, la sociología, la ética, la lógica, las ciencias políticas, la música, el teatro, la religión oriental y la poesía (Camnitzer, Farver \& Weiss, 1999).

Bajo esta perspectiva interdisciplinaria, el mail art, por su aproximación al arte conceptual, se muestra como una importante fuente de investigación en la que, a través de un estudio mediante el cual se articulen los conceptos de sus productores y el contexto histórico-social del periodo, se puedan descubrir los meandros de esta red y extraer conclusiones con más seguridad y justicia acerca de esta producción artística, hasta ahora bastante excluida de la historia “oficial" del arte. Como afirma Michael Crane (1984, p. 36):

To understand the effects and purposes of mail art, it is helpful to have knowledge of the history and transformation of art. Such knowledge can clarify the role of mail art in the larger field and dispel the myths and misperceptions that sometimes surround the network and its activities. In terms of mail art, it is useful to know who did what and when, general characteristics of productions, the behavioural and aesthetic attitudes that condition such productions, and trends and tendencies over the years. Such information will place correspondence art on a much wider plane where boundaries, direction, and meaning may be perceived wholly instead of piecemeal.

Según Freire (2006), surge, desde el punto de vista institucional de la memoria del arte contemporáneo, una especie de retorno de lo reprimido. Esto probablemente se debe a la reciente apertura de los archivos constituidos por la represión durante las dictaduras militares de los países de América Latina, lo que posibilita la rectificación de la historia oficial. En el contexto de la investigación artística post 60 , no sólo los archivos públicos son el centro de interés - una vez que la mayor parte de las obras de los años 70 están fuera de los acervos públicos y, por lo tanto, ausentes de la historia oficial (Freire, 2005)- como también los archivos privados que fueron constituidos durante 
varios años por los propios artistas. Estos archivos guardan, de manera bastante particular, los registros estéticos de historias aún no contadas, a la espera de nuevas significaciones.

En este contexto la voz de los artistas que participaron activamente del periodo también es una rica fuente de información. Esto se intensifica por el hecho de que el arte conceptual trae consigo al artista como crítico, o sea, que el artista participa intelectualmente del trabajo artístico -reivindicando esta posición- en todas las etapas: producción, circulación y crítica. En el arte conceptual el discurso participa de la obra, cuando no es él mismo la obra (Freire, 1999). De la misma forma, el artista correo participa activamente en todas las etapas que envuelven el hacer artístico, no sólo como productor y receptor del arte sino también como responsable de la circulación, exhibición y crítica de la producción, de manera que tanto sus archivos como sus escritos son valiosas fuentes de investigación.

Como ha afirmado Michael Lumb (1997) en su tesina de master el mail art es una "escultura social", de manera que en su estructura la inmaterialidad de la red es más relevante de que la materialidad que circula por ella. Bajo esta perspectiva, los nudos de la red -es decir, los artistas correo- son los elementos esenciales para su entendimiento. Sin embargo, como la red de mail art está formada por centenares de redes invisibles y dispersas por todo el planeta, el análisis de sus usuarios es un tema de una gran complejidad.

En este sentido, para hacer una aproximación del perfil del artista correo se ha decidido analizar dos fuentes diferentes de datos. Una de ellas ha sido la red social virtual de la Internacional Union of Mail-Artists - IUOMA (Grupo-1), que al estar disponible en línea permite que se obtengan datos de sus miles de participantes. La otra ha sido el cuestionario en línea contestado por un centenar de artistas correo (Grupo-2) realizado con la intención de profundizar en cuestiones pertinentes a esta investigación. El análisis de estos datos, bajo la perspectiva prosopográfica, ha hecho posible trazar un perfil aproximado de las personas que participan en la red de mail art.

Una vez elegido el grupo ha sido necesario establecer los parámetros que se van estudiar así como crear una base de datos para organizar la información. Los parámetros son las características que se pueden medir y calificar. En la investigación prosopográfica intervienen un gran numero de parámetros, de manera que se han elegido los que interesan directamente para cumplir los objetivos de la investigación. Para el Grupo-1 los parámetros elegidos fueron: sexo, procedencia, región, etapa de entrada en la red y motivación de participación. Para el Grupo-2, como ha sido elaborado un cuestionario 
más específico siendo posible definir otros parámetros de investigación. En este sentido, más allá de los parámetros para el Grupo-1, se han añadido los siguientes: contexto político, actitud/intencionalidad, lenguajes y temáticas utilizadas y actuación artística paralela.

\section{La Motivación de Participación Latinoamericana en International Union of Mail-Artists - IOUMA (Grupo-1)}

La Unión Internacional de los Artistas Correo (IUOMA) fue creada en 1988 por el artista correo holandés Rudd Janssen. Según su propio creador (Janssen, 2008), esta comunidad empezó como un juego, pero algunos de los artistas correo deseaban que se hiciera realidad, y lo han conseguido. Tanto es así, que los artistas la mencionan en sus currículos, utilizan su sello en sus páginas web, envíos o publicaciones, participan en el grupo de discusión de Yahoo, en la red social virtual Ning y en los proyectos o convocatorias propuestas por sus miembros.

Sus actividades se iniciaron en la red postal y rápidamente se expandieron hacía la red digital. En 2002, se ha creado un grupo de discusión a través de Yahoo Groups (http://groups.yahoo.com/group/iuoma/) que actualmente cuenta con más de medio millar de inscritos. Posteriormente, en 2008, a través de la plataforma Ning para la creación de redes sociales, se ha creado la comunidad virtual de IUOMA (http://iuoma-network.ning.com) que cuenta actualmente con más de dos mil participantes.

En esta red social algunas de las características de sus participantes como país de procedencia, género, inicio de la participación en la red de mail art, motivación de esta participación y otros datos personales como dirección web, residencial y electrónica son solicitadas para la subscripción en la red. Pese a que la contestación de estos ítems no era obligatoria, la gran mayoría de los afiliados los ha contestado, lo que ha hecho posible el análisis que se presenta a continuación.

En relación a Latinoamérica la participación de los 2000 integrantes de IUOMA analizados ha sido de 199 (9,83\% del total de participantes). De estos solamente 19 no han contestado su motivación de pertenecer a la red de mail art. Por lo tanto, han sido 180 las declaraciones analizadas. Para esta región las categorías Network (69), Producción Artística (64) y Expresión Utópica (59) han sido las más significativas. Las categorías Placer (38) y Interés Ocasional (37) se presentaron con menos expresividad que las anteriores. Siendo las menos significativas de todas las categorías Actividad Profesional (22) y 
Sistema Postal (11). Ha sido interesante observar que el patrón de ocurrencias para Latinoamérica fue muy semejante al patrón de Europa.

\section{Taxonomías para el Mail Art Latinoamericano (Grupo-2)}

Para facilitar la visualización de las características presentadas por cada uno de los artistas correo latinoamericanos entrevistados se crearon taxonomías en las cuales se pueden comparar y analizar los parámetros investigados.

Para visualizar mejor la relación entre el contexto geopolítico y la actitud/ intención de los entrevistados, se ha creado la "Taxonomía Contextual y Actitudinal". A través de esta relación, fue posible observar qué artistas correo han producido en una época dictatorial y si han tenido o no su trabajo censurado; además se ha verificado como estos artistas clasifican de manera general su actitud/intención en la participación de la red de mail art. De los 27 entrevistados, 12 dijeron tener una intención Artística, 10 Comunicativa y solo 5 Activista. Ahora bien, si relacionamos la actitud/intencionalidad con el contexto geopolítico vemos que no hay una relación directa entre una postura más marcadamente ideológica (Activista) y el hecho de producir bajo un régimen dictatorial, en este sentido solamente 3 entrevistados han demostrado esta relación.

La relación entre la intencionalidad de los entrevistados y las temáticas más recurrentes también aportan un interesante análisis que se pudo ver el la “Taxonomía Temática y Actitudinal". Se ha observado que todos los artistas que han afirmado su intencionalidad como Activista, también contestaron la temática Ideológica como algo recurrente en sus producciones, y, por lo tanto, han sido coherentes con su intención, demostrando que están comprometidos con cuestiones políticas, sociales, culturales o ecológicas. Por otro lado, un número significativo de entrevistados también ha señalado la temática Ideológica, asumiendo también una actitud Artística o Comunicativa, esto corrobora la idea -ya mencionada anteriormente- de que, pese a la elección de actitud, muchos entrevistados afirman que sus propuestas artísticas están siempre enmarcadas en un posicionamiento ideológico.

Una relación interesante que se puede establecer son las fases del mail art con los dispositivos más utilizados a través da "Taxonomía Contextual y Estratégica". En este análisis, se ha observado que las tarjetas postales son los dispositivos más utilizados en todas las fases, siendo únicamente tres los entrevistados que no las señalaron. Por otro lado, la poesía visual y los sellos y estampillas de artista -que también se mostraron como dispositivos muy 
utilizados- predominan en las cuatro primeras fases, teniendo el uso menos frecuente en la última fase. Los zines, por su parte, aparecen solamente en las dos últimas fases; mientras que los ready-mades son mencionados sólo en la última y el arte xerox apenas en las Fases III y IV; cabe destacar que estos tres dispositivos también son poco frecuentes en las respuestas.

La relación que se puede establecer entre las fases del mail art y la motivación de participación en la red por los participantes de América Latina se ha demostrado en la "Taxonomía Contextual y Motivacional". Se ha observado que para la gran mayoría de los latinoamericanos, independiente de la fase de adhesión, las principales motivaciones son las categorías Expresión utópica y Network. La categoría Producción Artística, pese a tener menor expresividad, también se distribuye por todas las fases. Por otro lado las categorías Interés ocasional y Placer son motivaciones que se observan a partir de la tercera fase de entrada en la red. Sin embargo, la categoría Sistema Postal que se presenta en muy pocas respuestas apenas aparece como motivación en las fases III y IV.

\section{Conclusiones}

A través de la presente investigación se ha podido estudiar en profundidad la red de mail art, no sólo en sus aspectos teóricos e históricos, sino también en su ámbito social y ha demostrado la complejidad de una práctica artística que es a la vez arte y comunicación. Sin embargo, la realización de este trabajo ha podido demostrar que el mail art aún se configura como una laguna en la historia del arte, pese a los esfuerzos de los propios artistas correo en publicar textos sobre el tema y a los pocos investigadores que realizaron sus tesis acerca de esta práctica artística.

La principal inquietud que ha motivado esta investigación ha sido la cuestión encontrada en la bibliografía de que el mail art latinoamericano se diferenciaba de lo demás por su carácter marcadamente político-ideológico. Esta relación directa entre arte y contexto político se mostraba demasiado taxativa para definir una práctica tan múltiple tanto en sujetos como en dispositivos. En este sentido, la línea inicial del estudio ha sido en primer lugar averiguar la bibliografía, para buscar las referencias teóricas e históricas, tanto las que apoyaban como las que contradecían esta idea, para después analizar específicamente los sujetos de esta práctica con la finalidad de entender su concepción y posición frente al mail art. 
A lo largo de la investigación se ha puesto en evidencia que la red de mail art es una estructura compleja e imbricada, principalmente si lo que se estudia son sus sujetos. Pero, a la vez, estudiar el mail art a partir de su red social ha permitido entender tanto las singularidades como las generalidades de sus participantes. De hecho, es la diversidad cultural lo que hace a la red de mail art tan atractiva.

Llegar a la investigación prosopográfica como forma de entender la red de mail art no ha sido un camino directo y obvio, se han dado muchas vueltas a las preguntas que instigaron este estudio, puesto que se ha visto a lo largo de la investigación teórica e histórica que no había forma de estudiar el mail art sin conocer a sus sujetos. Además, tampoco se podía estudiar el mail art de Latinoamérica sin compararlo con las demás regiones, en especial Norteamérica y Europa, regiones clave para el desarrollo de esta práctica artística. Sin embargo, el estudio del mail art a partir de sus sujetos y de la relación entre estas regiones no se muestra bajo la perspectiva dicotómica tradicional de la historia del arte de centro (Norteamérica y Europa) y periferia (Latinoamérica), sino al contrario, permite que se escriba una historia colectiva y descentralizada, como lo es la propia red.

El análisis del corpus de la investigación no sólo ha permitido conocer quiénes son los artistas que participan en la red de mail art, sino también sus motivaciones para participar. Por otro lado, este análisis también ha permitido comprobar de qué manera se caracteriza el mail art latinoamericano y si este realmente se diferencia del norteamericano o del europeo. En este sentido, se puede concluir que realmente el contexto político, en especial de los regímenes dictatoriales, pudo haber influido en algunos puntos de la red de mail art, específicamente en algunos de sus artistas o dispositivos, aunque sería una generalización demasiado arriesgada para caracterizar a todo un colectivo y a una práctica que se ha extendido tanto en el tiempo.

Además, los datos apuntaron que respecto a la intencionalidad Activista de los artistas correo fueron pocos los que asumieron esta actitud como determinante de su práctica, siendo sus intenciones Artística y Comunicativa mucho más significativas en todas las regiones estudiadas. Es verdad que hubo una mayor concentración de la posición reconocida como Activista entre los artistas latinoamericanos (62,5\% de los que han elegido esta opción, es decir, cinco artistas correo del total de ocho), sin embargo, en los comentarios generales de todas las nacionalidades se pudo averiguar que, pese a la elección por las otras alternativas, Artística o Comunicativa, algunos han señalado que el carácter ideológico está presente en su arte, o por qué entienden el arte 
como un compromiso político o por qué según las convocatorias y proyectos el tema conlleva un compromiso político-ideológico. Como ejemplo de estas posturas están las siguientes declaraciones:

_El "networker", al reflejar las relaciones que le dan origen en tanto producto de comunicación, no puede dejar de reproducir ideológicamente esa misma realidad. No sólo social o política, sino total. Es por ello que es tan difícil descontextualizar al arte de las demás áreas del quehacer humano. Tanto el sentido social como el político son consustanciales al arte. El arte se revela como forma sublimada de la conciencia social y, como tal, instrumento de conocimiento, cuya función es auxiliar con su aprobación o desaprobación a esa misma sociedad, pudiendo convertirse, de acuerdo con las circunstancias, en instrumento de cambio y transformación o de consolidación y preservación. (Artística, Clemente Padín, Uruguay)

- Obviamente poseo una posición ideológica y creo que el arte cumple un rol político, la función de la cultura lo es, pero mi intención como mail-artista no siempre es tan evidentemente política. Creo que el mail art en sí mismo como red es político en la medida que cuestiona precisamente la función del arte, artista, la comercialización, sobre los soportes, y otras problemáticas relacionadas con el circuito. (Artística, Osvaldo Morales Barraza, Chile)

_ Las tres respuestas son correctas. Mis intenciones y actitudes tienen relación con una producción activista, artística y comunicativa. (Artística, Guy Bleus, Bélgica)

- La parte más importante es la propia comunicación entre los participantes y la parte activista ya viene implícita en el propio medio del mail art, lo revolucionario desde el punto de vista artístico es la propia Red. Y también hay una parte como activista, pues tanto en el medio del mail art como en la vida real somos bichos sociales con inquietudes. (Comunicativa, Pere Sousa, España)

_ Comunicación libre y abierta es mi primera intención, pero cuando encuentro un proyecto o un contacto, las actitudes políticas o sociales son también muy importantes. Después de esto, todo es posible. (Comunicativa, Rosa Biagi, Italia)

- Yo contesto a la convocatoria. Si es política creo una pieza más política. Si es abstracta, abierta o técnica, creo una pieza basada en el tema. Generalmente, envío dibujos y pinturas originales en formato de tarjetas postales. (Comunicativa, Honoria Starbuck, EUA) 
Por otro lado, se ha observado que en relación a la motivación de los participantes respecto al Grupo-2 (cuestionarios), la categoría Expresión utópica es mucho más significativa en Latinoamérica que en el resto de regiones. En el mismo sentido, respecto a los temas más recurrentes y relacionados con algún tipo de compromiso ético e ideológico, también se ha podido observar que en Latinoamérica se destacan las temáticas Ideológica, Solidaria y Crítica en relación a las demás regiones. Estos datos pueden indicar que en el contexto latinoamericano se presenta una postura más idealizada y comprometida en la práctica del mail art.

Por todo lo mencionado, se concluye que no se puede demostrar efectivamente que el mail art latinoamericano está realmente caracterizado como un arte comprometido con la protesta y la denuncia, sin embargo, fue posible constatar que de hecho existe en Latinoamérica una mayor preocupación con las cuestiones de orden político y social.

\section{References}

Baroni, Vittore (1997). Arte Postale: guida al Network della corrispondenza creativa. Bertolo: AAA Edizioni.

Baroni, Vittore (1995). The hidden link: a network fable. En Welch, Chuck

(Ed.), Eternal Network: A Mail Art Anthology (157-163). Calgary,

Canadá: University of Calgary Press.

Bernard, Heliane (2005, septiembre). Au coeur de la communication. Revue

9 de COEUR, 5, 10-17, (Correspondance et Art postal), Paris, Éditions du Seuil.

Bleus, Guy (1984). Commonpress 56. Catálogo de Exposición. Tienen, Bélgica: Museum Het Toreke.

Blom, Ina (2007, mayo). How to (Not) Answer A Letter: Ray Johnson's

Postal Performance. PAJ - Journal of Performance and Art, 29 (2), 1-19. doi:10.1162/pajj.2007.29.2.1

Camnitzer, Luis (1997, noviembre). Una genealogía del arte conceptual latino-americano. Continente Sul Sur: Revista do Instituto Estadual do Livro, 6, 179-230.

Camnitzer, Luis (2009). Didáctica de la liberación: arte conceptualista latinoamericano. Murcia, España: Cendeac.

Camnitzer, Luis; Farver, Jane \& Weiss, Rachel (Eds.) (1999). Global 
Conceptualism: Points of Origin, 1950-1980. Catálogo de exposición. New York, EUA: Queens Museum of Art.

Crane, Michael (1984). A definition of Correspondence Art. En Crane, Michael \& Stofflet, Mary (Eds.), Correspondence Art: Source Book for the Network of International Postal Art Activity (3-38). San Francisco, EUA: Contemporany Art Press.

Crane, Michael \& Stofflet, Mary (Eds.). (1984). Correspondence Art: Source Book for the Network of International Postal Art Activity. San Francisco, EUA: Contemporany Art Press.

Freire, Cristina (1999). Poéticas do Processo: Arte Conceitual no Museu. São Paulo, Brasil: Iluminuras.

Freire, Cristina (2005). O presente-ausente da Arte nos Anos 70. En AA.VV. Anos 70: Trajetórias (147-156). São Paulo, Brasil: Iluminuras /Itaú Cultural.

Freire, Cristina (2006). Arte Conceitual. Rio de Janeiro, Brasil: Jorge Zahar. Deleuze, Gilles \& Guattari, Félix (1997). Mil mesetas: capitalismo y esquizofrenia. Valencia, España: Pré-textos.

Galloway, Alexander R . (2010). Networks. En Mitchell, William J. T. \& Hansen, Mark B. N. (Eds.), Critical terms for media studies (280-296).

Chicago, EUA: University of Chicago.

Gilbert, Zanna (2009, otoño-invierno). Ideological Conceptualism and Latin America: Politics, Neoprimitivism and Consumption. Re·bus, 4, 1-15.

Recuperado de http://www.essex.ac.uk/arthistory/research/pdfs/rebus issue_4/Gilbert.pdf

Lippard, Lucy (2004). Seis años: La desmaterialización del objeto artístico de 1966 a 1972. Madrid, España: Akal.

Lumb, Michael (1997). Mailart 1955 to 1995: Democratic Art as Social

Sculpture. (Tesis inédita de maestría). School of World Art Studies and

Museology, University of East Anglia, Norwich, Inglaterra. Recuperado de http://keithbates.co.uk/thesis_michael_lumb.pdf

Marchán Fiz, Simon (1994). Del arte objetual al arte de concepto - 1960 1974. Madrid, España: Akal.

Marzona, Daniel (2005). Arte Conceptual. Köln, Alemania: Taschen. Osborne, Peter (2006). Arte conceptual. Londres, Inglaterra: Phaidon. Wood, Paul (2002). Arte Conceitual. São Paulo, Brasil: Cosac \& Naify. 
Fabiane Pianowski: Profesora Asistente de la Universidade Federal do Vale do São Francisco (UNIVASF).

Contact Address: Universidade Federal do Vale do São Francisco, Colegiado de Artes visuais. Avenida Antônio Carlos Magalhães, 510 Country Club. 48902300 - Juazeiro, BA - Brasil Telefone: (74) 21027642

E-mail address: fabiane.pianowski@gmail.com fabiane.pianowski@univasf.edu.br 